DOI 10.1007/s10958-019-04512-6

Journal of Mathematical Sciences, Vol. 242, No. 6, November, 2019

\title{
In Memory of Professor Sir Michael Francis Atiyah
}

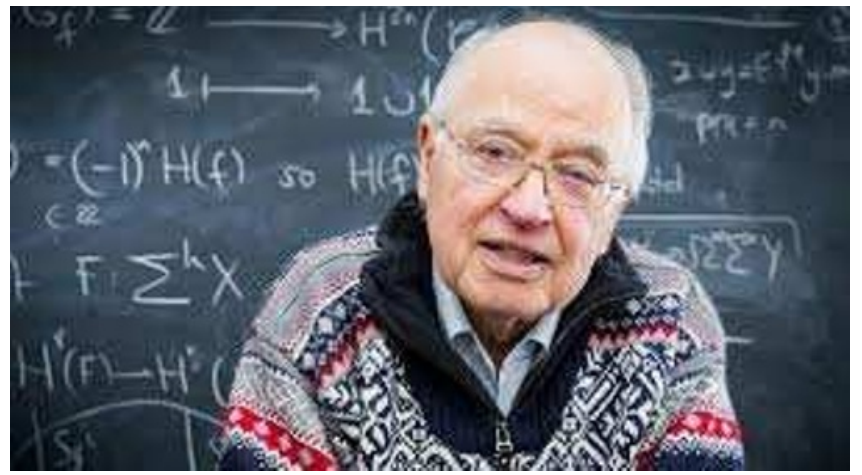

June 13, 1931 - December 22, 2018

The Editorial Board of the international journal "Ukrainian Mathematical Bulletin" has learnt with great sadness of the death of Professor Sir Michael Atiyah on January 11, 2019. Michael Atiyah was a brilliant mathematician and a towering figure who dominated the international mathematical landscape for over half a century, a Foreign Member of the NAS of Ukraine, a permanent member of the International Editorial Board of our journal. Professor Sir Michael Atiyah will be remembered for a long time for his fundamental contribution to the contemporary mathematicsn and the outstanding role in building the new bridges between mathematics and theoretical physics, as well as for the formation and development of our journal. 